\title{
SWING, VOLTAGE STABILITY AND POWER TRANSFER CAPABILITY IN TRANSMISSION SYSTEM WITH UPFC: THE ART OF STATUS
}

\author{
Rishi Kumar Singh ${ }^{1}$, N.P. Patidar ${ }^{2}$ \\ ${ }^{1}$ Assistant Professor, EED, MANIT, Bhopal, M.P., India \\ ${ }^{2}$ Associate Professor, MANIT, Bhopal, M.P., India
}

\begin{abstract}
In modern era, the increasing size of the power system, to maximize the use of existing systems and to provide adequate voltage support is an emphasis on finding solutions. This flexibility is needed electricity. Better placed than the Flexible AC Transmission Systems (FACTS) to control the flow of electricity, and to provide voltage support can be effective in turn resulting in less damage. The impact of these tools on line flow and bus voltage profile at random algorithm to determine the optimal number of ratings have been studied by keeping them better.
\end{abstract}

The FACTS devices are expensive cause of that FACTS type, number and location of the FACTS devices is very important, for decide the optimal location and parameters of FACTS devices. FACTS are used in the following purposes: Transmission pricing issues by maximizing social welfare with or without consideration of FACTS' costs; Better utilization of FACT by maximizing FACTS devices total transferred power; Reactive power or voltage control by minimizing transmission losses, or voltage fluctuation. Increase system's security under emergency by minimizing transmission lines loadability.

Power flow control, a current long transmission line, plays an important role within the energy system. The letter swings, longdistance transmission line voltage and power flow control in unified power flow controller (UPFC) based compensation associated series or shunt FACTS devices are employed. Devices such as the proposed transmission line, between the end of the sending and receiving end to the transmission line is used in places as different. Here also deals with determining the optimum placement of Flexible AC Transmission Systems (FACTS) damping out swings, voltage and improves power transfer devices for a long transmission line. Here the concept of compensation mid-point of facts is presented for optimal placement.

Keywords: Stability, first swings, rotor angle, power transfer, Flexible AC Transmission Systems (FACTS), Unified Power Flow Controller (UPFC), reactive power.

\section{INTRODUCTION}

Flexible AC Transmission Systems (FACTS) has received much attention in the past two decades. It's a transmission system voltage, power flow, stability control, etc. uses highcurrent power electronic devices. Some forms of FACTS devices and others are still under development, prototype installation [ 3 ] are already available for FACTS devices such as series, shunt or as a combination of series and shunt transmission line can be connected in various ways. For example, the static VAR compensator ( SVC) and static synchronous compensator (STATCOM) are connected in shunt static synchronous series compensator (SSSC) and thyristor controlled series capacitor (TCSC) are connected in series, thyristor -controlled phase (TCPST transformer transfer ) and unified power flow controller (UPFC) are connected with a series and FACTS devices IEEE article [ 4 ] are described. Permit limits if the same degree of thermal stability [5-8] facts maintaining equipment, a line of very effective and are able to increase the power transfer capability.
This paper is the ability to transfer power line is connected to shunt FACTS device models to consider when examining the effect of stability on the real line. Transmission is often an option for modern generation and transmission capacity and reduces the need for generation resources means. Costs as well as difficulties encountered during the construction of new transmission lines, limit the transfer of power available. In many cases, economic power or transmission capacity is constrained by splitting reserved. Flexible AC Transmission Systems (FACTS) technology to control power flow and existing transmission lines to increase usable capacity opens up new opportunities.

There is a big mess, upset this balance and other machines [3] in relation to the ' swinging ' is starting. Here transient stability of a short circuit on a transmission line as a serious disturbance, subject to the ability of the power system to maintain synchronism [5 ]. UPFC series and shunt system in combination of the system are connected to the FACTS of the 
family members and the voltage swing and stability [6] are very effective in improving.

At the mid-point along the transmission line [7] sited the shunt FACTS devices give the maximum benefit from the support that has seen steady voltage. Evidence of an increase in the maximum power transfer capacity transmission lines to reduce resistance and capacitance, which is a reasonable assumption, neglects the line is based on a simple model. The first swing stability of the system is affected by the choice of different models of the transmission line that has been observed [10].

This paper studies a swing and line voltage stability of the actual (true) to model the facts in the different positions of a long transmission line (UPFC) device allows comparing the distinct results found. The real power flow model for precise line with a predefined direction, toward the end of the sending device, a fact that needs to be located slightly off-center is shown.

In this work, UPFC phasor model of the mid-point of a twozone system is used to check spots. In computer simulation, short circuit is a serious disturbance condition ( ie, a threephase fault) under the simulation. Compare these results with the power transfer capability and voltage swing FACTS devices in improving stability reflects the impact of the midpoint location.

\section{POWER TRANSFER CAPABILITY AND}

\section{SYSTEM STABILITY}

\subsection{Definition of Stability for a System}

Let the equilibrium state of the system, the occurrence of a disturbance and the system still is able to achieve a state of balance it is considered stable. The system also in the proximity of the initial equilibrium point if converges to an equilibrium position is considered stable. Physical condition of the system with respect to time that something like this is different physiological variables increases, the system [11] is considered unstable.

Therefore, the system machines in synchronism with each other, the forces tending to hold off an upset when enough is said to be stable. The most worrisome feature of the system and the stability of power system behavior after a disturbance.

\subsection{Need for Power System Stability}

Electrical systems are constantly changing industry, where there is a field. Power industry to lower prices and better power efficiency are restructuring to meet more users. As they are interconnected power systems are becoming more complex. Load demand increases linearly with the increase in users. Transfer capability limit of stability within the system since the event, due to economic reasons, need to ensure power system stability and reliability.

Different types of rotor angle stability of power system stability, frequency stability and voltage stability [11] have been classified as. Fig-1 power system stability [1] shows the classification.

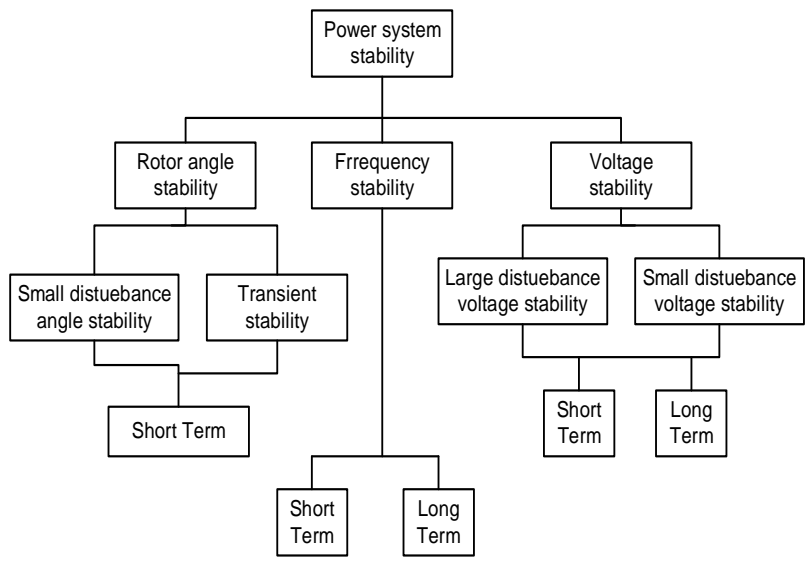

Fig-1: Classification of power system stability

\subsection{Stable First Swing}

Power outages rise against the catastrophic economic operation system during the inter-relations, and strategic coverage and improved reliability are becoming more complex. Transmission network reinforcement and to avoid environmental objections include the capital costs are now under more stress than ever before.

These trends need to operate close to the stability limit is a system, and disturbances of the system is more vulnerable electrical fast transient and dynamic stability problems. Utility companies operating security limit the risk of engineers to perform off-line transient stability simulation face a huge number. These limits again for on-line dynamic security monitoring control center are used throughout the energy management system.

Definition: An electric system with a peak value from the start of the severely disturbed machines (SDM) increases ( or decreases ) the inertia (COI) reference frame later point in the centre angle reaches the first is said to be the stable swing angle begins to return to stable equilibrium point [13].

Extreme angle of the SDMS, and therefore, zero speed, the first swing stability guarantees the existence of the system. On the other hand, the system is the system increases (or decreases) at least one of the machines and ultimately, the fault angle monotonically (CO1 reference frame over 1800) is infinitely variable is considered first swing. 
First swing stability of the machine sees the transformation of machine speed and power at the wrong time can be checked quickly in the countryside. Its lightning fast speed and acceleration are still negative, while a stationary machine during the peak angle fault (or zero speed) reaches:

$$
\begin{aligned}
& \omega=0 \\
& \mathrm{~Pa}<0
\end{aligned}
$$

Serious conditions after a machine zero speed and power fault simultaneous occurrence up to the period are characterized by:

$$
\begin{gathered}
\omega=0 \\
P a=0
\end{gathered}
$$

The above criteria have a tendency to run out of moves by acceleration that is valid for a machine that can be mentioned here. For a decelerating machine, stationary above criteria and criteria for critical situations by comparing the left-hand side of the equation to be modified by adding a negative signal are rejected from the machine zero speeds as the fast power index can be considered as the degree of stability of the machine. Similarly, by comparing the criteria for volatile and critical situations, no high degree of fluctuation in the power of machine to machine speed can be considered as an index. The stability/instability of the machine after a fault during the determination of the degree and speed of the machine are required to accelerate powers [13-15].

\subsection{First Swing Stability}

Power system fault (short circuit), causing rapid changes in the position of power. Revenge electrical power from the generator, power flow and load changes affect demand.

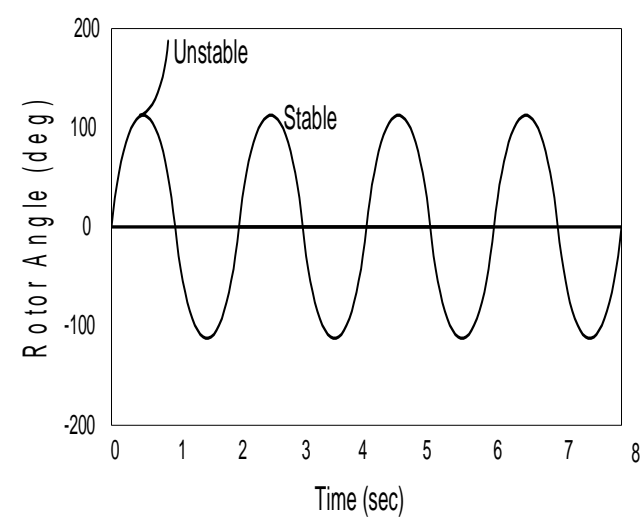

Fig-2: Rotor angle swings

Generator shaft through the fault before the fault will receive approximately the same mechanical input. The mechanical input and rest of system in relation to each individual rotor speed up or slow down, the power, the power imbalance between the causes. Individual rate of change of power deviation and rotor inertia is determined by each generator. Differences in the power system will increase the angle of the rotor angle cannot be huge difference. Therefore, when the fault is cleared (after 0.1) as the generator power system has fallen out of step, grid node voltage will be zero in some parts of the grid the generator started to works as Motors. Sufficiently small-angle deviation between the generator rotors will be restored; since we need first swing damping of oscillations $[13,14]$.

\subsection{Rotor Angle Stability (Electrical Oscillation)}

Sudden changes in the power system with different timeframes are associated with a number of events. In the first-phase electrical, properties are adjusted very quickly to the new situation. The share of electricity generation varies between different generators and also in load demand causes changes. Accordingly, changes in power flow through the grid. In the second phase of mechanical and electrical generator producing an input unbalance between mechanical generators are due to a change of pace. Individual rate of change in speed deviation and rotor inertia is decided by force. Generators with different rates of speed, turning the rotor angle of each generator will start to deviate from the predisturbance value. It is a generator for electricity to the grid due to the imbalance that causes a change in the flow. In Phase, III safety and control come into play. If any defects are cut - usually a short time delay (the problems associated with high currents break) after. Separation causes a transient fault. Steady-state conditions for regaining control grid are trying to restore. They said they are controlled with different speeds depending on the function. We then return to equilibrium between consumption and output voltage of the voltage regulators, and governor's turbine generator tries to restore the mechanical input adjusted. These variations are oscillatory in nature and very lightly damped [13-15].

The rotor angle oscillations can arise in the grid without any apparent reason. Weak transmission lines, fast and powerful voltage regulators and other types of control power flow in the grid oscillations can stand high above. Generators located close to each other, and the system is very low frequency (below 0.1-0.2 Hz) with an oscillating machine to another can end up with groups. Many generator tie lines then move into another group can become a heavy load. As soon as possible, it is important to damp these oscillations. They are mechanical wear in power plants; power quality problems (flicker, etc.) may be due to causes. Further disturbances occur; the system is even more vulnerable. It can be identified in two main ways.

\subsection{Concepts Transmission Transfer Capability}

Transmission transfer capability is the key basic concepts described below. NERC many other conditions relating to the transfer capability of the transmission transfer capability in May 1995 is explored in detail in the reference document. 
That document concepts and terminology, an open- air environment [16] still apply.

\subsubsection{Transfer Capacity}

The units of transfer capability are in terms of power, typically megawatts (MW) expressed. In this context, "area " One power system, power pool, control area, sub- area, or NERC region, or any of them be a part of transfer capacity is directional in nature. The Area B to Area A and A Area to Area B generally [16, 17] is not equal to the transfer capability, the ability to transfer from the region.

\section{FACTS DEVICES INTO A POWER SYSTEM}

FACTS controllers, gate turn-off capability with a gate turnoff thyristor devices or electrical equipment can be based. FACTS controllers, high-voltage AC transmission lines, voltage, impedance and phase angles are used for dynamic control. Two areas under study used the following facts in the power system controllers are discussed briefly the basic principles [1-4].

\subsection{Unified Power Flow Controller (UPFC)}

A shunt UPFC controller (STATCOM) and as shown in the figure below, a common DC bus through a series of the interconnected controller (SSSC) is a combination of uses.

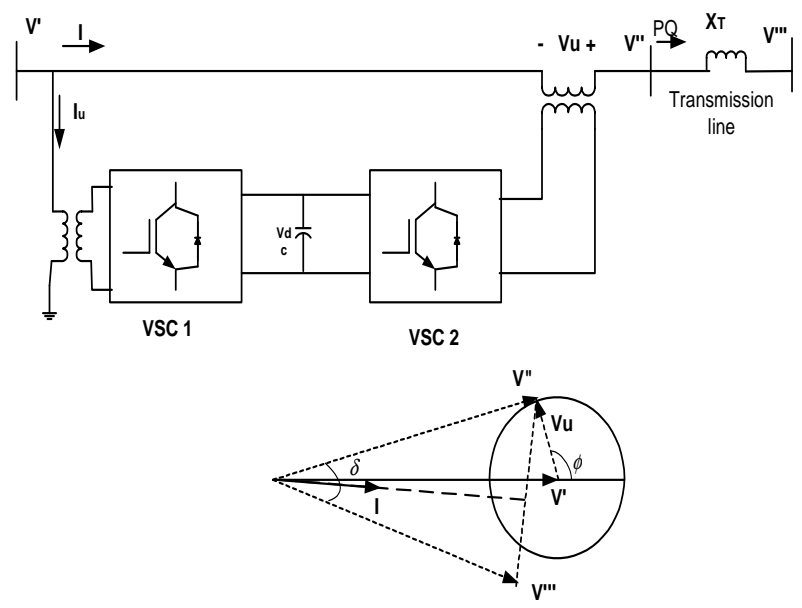

Fig-3: Single -line diagram of a UPFC and phasor diagrams of Voltages and currents

$$
\mathrm{P}=\frac{\mathrm{V}^{\prime \prime} \mathrm{V}^{\prime \prime} \sin \delta}{\mathrm{X}_{\mathrm{T}}} ; \quad \mathrm{Q}=\frac{\mathrm{V}^{\prime \prime}\left(\mathrm{V}^{\prime \prime}-\mathrm{V}^{\prime \prime} \cos \delta\right)}{\mathrm{X}_{\mathrm{T}}}
$$

As $\Phi$ is different, the two-line voltage, V" and V" also vary between the phase shift $\delta$ ends. Both the active power $\mathrm{P}$ and reactive power $\mathrm{Q}[17,2]$ can be controlled at the end of a line that is transmitted.
In addition to allowing control of active and reactive power line, UPFC provides an additional degree of freedom. As STATCOM converter operating in a shunt, reactive power absorbed or generated by the voltage V1 controls.

Series and shunt converters connected on the secondary side of a coupling transformer Voltage Sourced Converter (VSC) use. VSCs a voltage from a DC voltage source to synthesize forced commutated power electronic devices (GTOs, IGBTs or IGCTs) use. VSCs common capacitor connected on the DC side acts as a DC voltage source. Two VSCs VSC technologies can be used for:

GTO based square wave inverters and special interconnection transformers using VSC. Typically, four three- level inverter to produce a 48- step voltage waveform is used. Special interconnection transformers contained in square waves generated by an individual inverter is used to neutralize the harmonics. In this type of VSC, VDC voltage is proportional to the voltage fundamental component. The Committee injection voltage is varied to control.

VSC using IGBT -based PWM inverters. Some of this type of inverter $\mathrm{kHz}$ with a typical chopping frequency to synthesize a sinusoidal wave with a dc voltage pulse width modulation (PWM) technique uses. Harmonics VSC cancels them by connecting the AC filters are in favor. This type of VSC uses a fixed DC voltage Vdc. Modulation index is varied by changing the voltage of the PWM modulator. UPFC (phasor type) block model, an IGBT based UPFC. Details of the inverter and harmonics are not represented; however, also a GTO based on transient stability studies UPFC $[2,17]$ can be used to model.

\section{LOCATION OF SHUNT FACTS DEVICES IN TWO-AREA POWER SYSTEM}

Previous works on the subject sited at the mid-point of the transmission line when the constant voltage shunt devices supporting facts prove that the maximum benefit. Evidence of increased stability and maximum power transfer capability of the line model is based on a simplified version of neglecting line resistance and capacitance. Based on the simple model of a transmission line or the center line between facts combined shunt -series has proven to be the optimal location in the equipment. Line is the actual model, the fact that the highest possible return device [3] should be placed slightly off-center to get that is found.

Sitting mid-point of reactive power control is most effective. Transmission line transient stability and thermal limits must be operating below the threshold. Increase STATCOM first swing stability analysis [5] SVC is better than the shows. Siddhartha Panda, Ram Narayan N. Patel [ 10] placed at the mid-point of a long transmission line, the shunt Flexible AC Transmission Systems (FACTS ) devices investigated 
regarding, for power networks play an important role in controlling reactive power flow and both voltage fluctuations and transient stability within the system. This paper predefined direction of real power flow in a long transmission line to improve transient stability is also related to the placement of a shunt FACTS device. It is placed slightly offcenter toward the sending end when the FACTS devices, delivering better performance in improving transient stability and space that has been seen.

\section{CONCLUSIONS}

This work deals with the application of UPFC. Model swing, voltage stability analyses are applied, and cover a wide range of power transfer capability. In this work, the effects of UPFC in the power transmission path are analyzed, and the conclusion can be given by analysis of performance.

The study is divided into different sections for clarity. First, the optimal location of shunt FACTS devices or low- voltage mid- point location that is just a given operating condition was determined. Unlike previous works in this area, we have a long line affects the optimal position, which is the actual line model. The next section discusses how the flow line, keeping the UPFC impact test system performance with four generators. Static and dynamic changes throughout the examination system while the generator loading, flow separation line, swings and tests have been studying the effects of system voltage stability.

\section{REFERENCES}

[1] P. Kundur, Power System Stability and Control, McGraw-Hill, 1994.

[2] N. G. Hingorani, L. Gyugyi, "Understanding FACTS; Concepts and Technology of Flexible AC Transmission Systems," IEEE Press book, 2000.

[3] S. Panda and R. N. Patel, 'Transient Stability Improvement by Optimally Located STATCOMs Employing Genetic Algorithm', Intl J. Energy Technology and Policy, 5(4) (2007), 404-421.

[4] R. Patel and K. V. Pagalthivarthi, 'MATLAB-Based modelling of power system components in transient stability analysis', Intl J. Modelling and Simulation, 25(1) (2005), 43-50.

[5] P. Kundur, J. Paserba, V. Ajjarapu, G. Andersson, A. Bose, C. Canizares, N. Hatziargyriou, D. Hill, A. Stankovic, C. Taylor, T. V. Cutsem and V. Vittal, 'Definition and classification of power system stability', IEEE Trans. Power Systems, 19(2) (2004), 1387-1401.

[6] L. Gyugyi, 'Power electronics in electric utilities: static VAr compensators', IEEE Proc., 76 (1988), 483-494.

[7] L. Gyugyi, 'Dynamic compensation of a.c. transmission lines by solid-state synchronous voltage sources', IEEE Trans. Power Delivery, 9(2) (1994), 904-911.

[8] B. T. Ooi, M. Kazerani, R. Marceau, Z. Wolanski, F. D. Galiana, D. Mcgills and G. Joos, 'Mid-point siting of
FACTS devices in transmission lines', IEEE Trans. Power Delivery, 112 (1997), 1717- 1722.

[9] M. H. Haque, 'Optimal location of shunt FACTS devices in long transmission lines', IEE Proc. Power Gen. Trans. Distrib., 147 (2000), 218-222.

[10] S. Panda and R. N. Patel, 'Optimal location of shunt FACTS controllers for transient stability improvement employing genetic algorithms', Electric Power Components and Systems, 35(2) (2007), 189-203.

[11] K.R.Padiyar "FACTS Controllers in power transmission and distribution",New Age International Publishers, 2007.

[12] Y.H. Song and A.T. Johns, "Flexible ac transmission systems (FACTS)", The Institute of Electrical Engineers, London, 1999.

[13] M. H. Haque, "Evaluation of First Swing Stability of a Large Power System With Various FACTS Devices" IEEE TRANSACTIONS ON POWER SYSTEMS, VOL. 23, NO. 3, AUGUST 2008, pp. 1144-1151.

[14] Anuradha S. Deshpande, Kadam Paresh A., Rana Vikas M. "First Swing Stability of The Power System Using Facts Device" National Conference on Recent Trends in Engineering \& Technology, 13-14 May 2011, pp.15 .

[15] M.H. Haque, "Damping improvement using facts devices". Electrical Power Syst. Res. Volume 76, Issues 9-10, June 2006.

[16] North American Electric Reliability Council (NERC) report 'Available Transfer Capability Definitions and Determination' June 1996.

[17] http//www.ieexplore.com, www.mathwork.com, www.google.com, etc. 